\title{
Variasi Ikan Sapu-Sapu (Loricariidae) Berdasarkan Karakter Morfologi Di Perairan Ciliwung
}

\author{
Dewi Elfidasari ${ }^{1}$, Fatihah Dinul Qoyyimah ${ }^{2}$, Melta Rini Fahmi ${ }^{3}$, Riris Lindiawati Puspitasari ${ }^{4}$ \\ ${ }^{1,2,4}$ Program Studi Biologi, Fakultas Sains dan Teknologi, Universitas Al Azhar Indonesia. Komplek \\ Masjid Agung Al Azhar, Jl. Sisingamangaraja, Kebayoran Baru, Jakarta 12110 \\ ${ }^{3}$ Balai Penelitian dan Pengembangan Budidaya Ikan Hias, Pusat Penelitian dan Pengembangan \\ Perikanan, Kementrian Kelautan dan Perikanan. Jl. Perikanan No. 13 Pancoran Mas Kota Depok Jawa \\ Barat 16436. Tel (021) 7520482
}

Penulis untuk Korespondensi/e-mail: d_elfidasari@uai.ac.id

Abstrak - Ikan sapu-sapu Genus Pterygoplichthys masih sulit dibedakan berdasarkan karakter morfologinya. Bentuk kepala ikan Ordo Siluriformes adalah "picak" atau depressed dengan bagian abdomen memiliki pola titik-titik putih besar dengan beberapa pola menyatu yang dilengkapi dengan mulut. Beberapa metode identifikasi dilakukan berdasarkan karakter morfologi yang meliputi bentuk kepala, silur pada bagian lateral dan melihat pola abdomen. Identifikasi berdasarkan pola abdomen dapat dilakukan dengan melihat literatur yang ada. Variasi morfologi ikan sapu-sapu Genus Pterygoplichthys asal sungai Ciliwung menunjukkan bahwa berdasarkan pola kepala dan pola lateral persentase individu P.pardalis lebih dominan dibandingkan spesies lain yaitu $76 \%$ dan $46 \%$, sedangkan berdasarkan pola abdomen menunjukkan bahwa hybrid merupakan jenis yang dominan (78\%).

Kata kunci - Ikan sapu-sapu, Sungai Ciliwung, Karakter morfologi, Pola abdomen

Abstract - Suckermouth armored catfish is one of the native catfish from the Amazon river. The fish is diversed in several countries but known as an invasive species, one of them is in Jakarta. Suckermouth armored catfish genus at Indonesia is Pterygoplichthys. Identification by looking at the morphological character of the fish is still difficult. Therefore, the identification is done by looking at the fish abdominal pattern. Sampling was done by searching at Ciliwung River, randomly obtained from the fisherman. The fish is identified by looking at the existing literature. The results show that allegedly there are two species of fish at Ciliwung River, which are Pterygoplichthys pardalis and Pterygoplichthys disjunctivus, also inter-grade fish species.

Keywords - Suckermouth armored catfish, Ciliwung River, Morphology characteristic, Abdomenal pattern

\section{PENDAHULUAN}

$\mathrm{I}$ kan sapu-sapu secara morfologi memiliki tubuh yang ditutupi dengan sisik keras yang fleksibel (Gambar 1). Bentuk kepala ikan Ordo Siluriformes adalah "picak" atau depressed (Bhagawati et al. 2013). Bagian abdomen memiliki pola titik-titik putih besar dengan beberapa pola menyatu yang dilengkapi dengan mulut penghisap pada bagian bawah (Hoover $e t$ al. 2004).

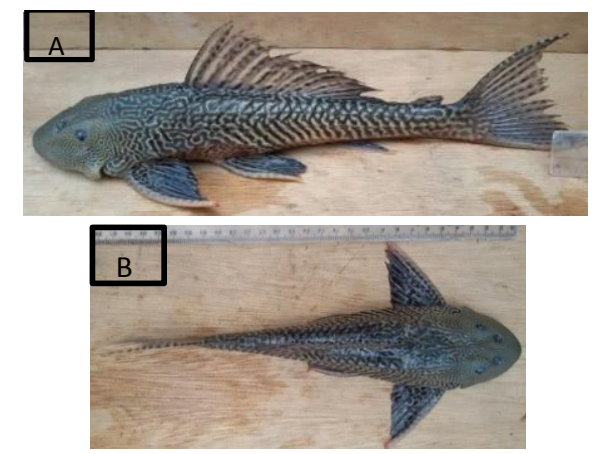

Gambar 1. Morfologi Ikan Sapu-Sapu [a] tampak samping dan [b] tampak atas 
Terdapat sirip dorsal sebanyak 9-14 buah pada ikan sapu-sapu jenis Pterygoplichthys disjunctivus. Sirip dada dilengkapi dengan duri kecil yang berbentuk seperti gigi. Umumnya ikan sapu-sapu Pterygoplichthys mampu mencapai ukuran $40 \mathrm{~cm}$ atau lebih. Ikan tersebut dapat mencapai panjang $35 \mathrm{~cm}$ dalam waktu 2 tahun (Page 1994; Nico \& Martin 2001). Spesies $P$. disjunctivus seringkali disamakan dengan P.pardalis. Kedua spesies tersebut diketahui memiliki perbedaan pada bagian abdomen. P.disjunctivus memiliki pola yang berlekuk-lekuk sedangkan P.pardalis dengan pola titik-titik hitam yang terpisah (Page 1994).

Ikan sapu-sapu merupakan salah satu jenis ikan yang termasuk dalam invasive species. Invasive species dapat menjadi predator maupun kompetitor terhadap spesies asli (Hill \& Lodge 1999), selain itu ikan ini dapat menyebabkan hibridisasi tidak terduga (Mallet 2007). Keberadaan ikan sapu-sapu dapat diketahui dari lubang-lubang yang terlihat dalam bentuk kumpulan di sepanjang lereng pinggir sungai. Lubang tersebut berfungsi sebagai tempat peletakkan telur ikan (Nico et al 2012).

Ikan sapu-sapu dapat ditemukan pada berbagai lokasi, salah satunya adalah Sungai Ciliwung. Sungai tersebut merupakan aliran yang berasal dari Gunung Pangrango yang melewati Bogor, Depok, dan berakhir pada teluk Jakarta (Hendrawan 2008). Sungai ciliwung termasuk sungai di Indonesia yang paling banyak dimanfaatkan oleh masyarakat. Sungai Ciliwung merupakan salah satu sungai di dunia yang memiliki tingkat polusi sangat tinggi. Penyebab polusi terbesar di sungai tersebut adalah limbah manusia (International River Foundation 2011).

Berdasarkan studi literatur yang dilakukan oleh Wowor (2010), pada tahun 1910 ditemukan sebanyak 187 jenis ikan yang hidup pada DAS Ciliwung. Tahun 2009 hanya terdapat 20 jenis ikan dengan 5 jenis lainnya adalah jenis asing. Penurunan keanekaragaman jenis ikan di Sungai Ciliwung tercatat mencapai $92,5 \%$ pada tahun 2010. Penurunan populasi ikan tersebut dapat disebabkan oleh keberadaan ikan sapusapu, karena tidak terdapat predator yang memakan ikan tersebut. Hal tersebut menyebabkan ikan sapu-sapu dapat mendominasi suatu wilayah perairan (Hadiaty 2011).

Penelitian ini dilakukan untuk menganalisa variasi ikan sapu-sapu di Sungai Ciliwung berdasarkan karakter morfologi.

\section{METODE PENELITIAN}

Penelitian dilakukan selama 4 bulan, mulai dari bulan Agustus-November 2015. Objek penelitian adalah ikan sapu-sapu yang diperoleh dari Sungai Ciliwung daerah Rindam Jaya sampai Bidara Cina. Identifikasi objek dilakukan di Labaoratorium Biologi Universitas Al Azhar Indonesia, Jakarta Selatan.

Alat yang digunakan pada penelitian ini adalah kontainer, penggaris dengan ketelitian $0,5 \mathrm{~mm}$, kamera, caliper, jarum suntik, dan alat untuk penandaan (tagging). Bahan yang diperlukan dalam penelitian ini yaitu ikan sapu-sapu dan pakan.

\section{Metode Penelitian}

Penelitian yang dilakukan terdiri koleksi sampel, pengamatan variasi morfologi, pengamatan pola abdomen dan analisa data.

\section{Koleksi Sampel}

Sampel diperoleh dari pengumpul ikan sapusapu di sepanjang aliran sungai Ciliwung. Sampel yang telah diperoleh selanjutnya dibawa ke laboratorium untuk diamati. Sampel yang diperoleh dibius dengan menggunakan kloroform dan diawetkan, difoto dan diamati variasi morfologinya.

\section{Pengamatan Variasi Morfologi}

Variasi morfologi yang diamati meliputi sirip, bentuk tubuh, bentuk kepala, mulut, bagian tubuh lateral, dan bagian abdomen ikan. Sampel yang telah diamati morfologinya, kemudian dilakukan pengamatan terhadap pola kepala, pola lateral, dan pola abdomen.

\section{Pengamatan Pola Kepala, Pola Lateral, dan Pola Abdomen}

Pengamatan pola kepala dan pola lateral merujuk pada Armbruster \& Page (2006), sedangkan pengamatan pola abdomen merujuk pada Bijukumar et al. (2015) dan Wu et al. (2011). Sampel selanjutnya difoto dan diamati, 
kemudian dilanjutkan dengan pengukuran karakter morfometrik dan meristik.

\section{HASIL DAN PEMBAHASAN}

Identifikasi ikan sapu-sapu berdasarkan karakter morfologi dapat dilakukan dengan melihat pola kepala, pola lateral, dan pola abdomen (Page 1994; Page \& Robins 2006; Armbruster \& Page 2006; Wu et al. 2011; Bijukumar et al. 2015). Identifikasi berdasarkan pola kepala terbagi menjadi pola garis terang geometrik (Gambar 2A) yang menunjukkan spesies P.pardalis, serta pola titik dan blotches (Gambar 2B) menunjukkan spesies P.disjunctivus (Armbruster \& Page 2006).

Hasil identifikasi berdasarkan pola kepala menunjukkan ikan sapu-sapu sungai Ciliwung adalah $\quad 76 \% \quad$ P.pardalis, $4 \%$ adalah P.disjunctivus, dan $20 \%$ adalah ikan dengan pola acak
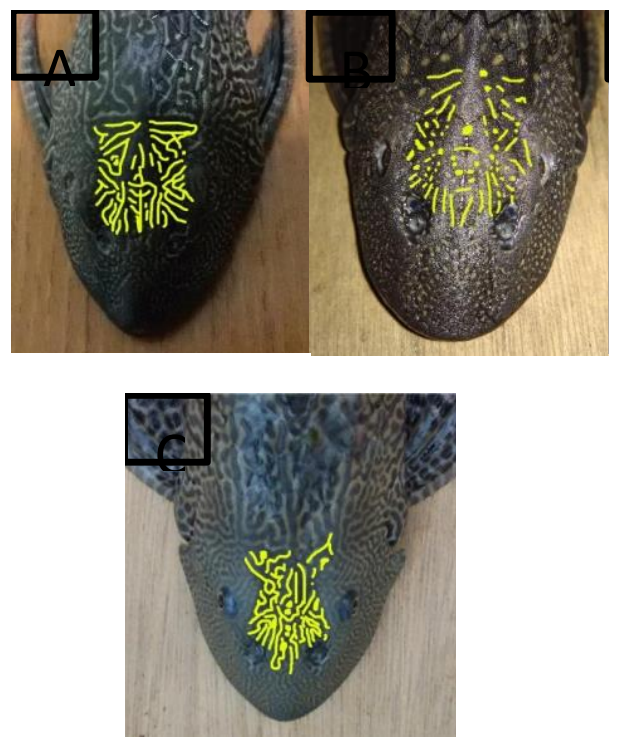

Gambar 2. Perbedaan pola kepala ikan (A) P.pardalis; (B) P.disjunctivus; (C) pola acak

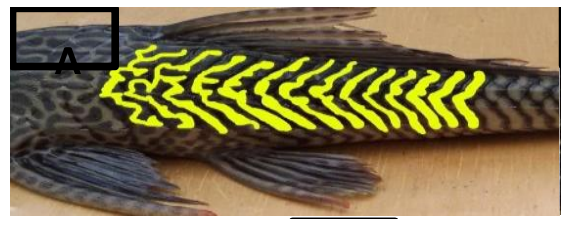

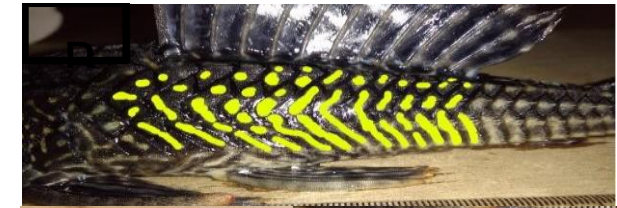

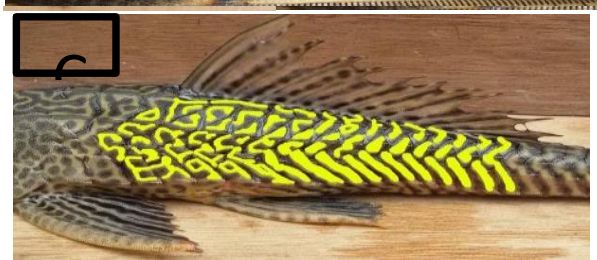

Gambar 3. Perbedaan pola lateral ikan (A)

P.pardalis; (B) P.disjunctivus; (C) pola acak

Identifikasi ikan berdasarkan pola lateral terbagi menjadi pola menyatu membentuk chevrons $(<)$ yang menunjukkan spesies P.pardalis, serta pola terpisah dan tidak membentuk chevrons yang menunjukkan spesies P.disjunctivus (Armbruster \& Page 2006) (Gambar 3).

Hasil identifikasi berdasarkan pola lateral menunjukkan P.pardalis sebesar $46 \%$, P.disjunctivus sebesar $12 \%$, dan pola acak sebesar $42 \%$. Penggambaran spesies dari Pterygoplichthys masih sulit dibedakan, hal ini disebabkan adanya beberapa spesies yang memiliki kemiripan (P.anitsisi, P.multiradiatus, $\quad$ P.pardalis, dan P.disjunctivus). Oleh karena itu identifikasi Genus Pterygoplichthys dilakukan dengan melihat pola abdomennya (Nico et al. 2012).

Ikan sapu-sapu asal sungai Ciliwung memiliki 3 pola abdomen yang berbeda. Pola spot hitam yang menunjukkan spesies P.pardalis, pola berlekuklekuk atau vermikulasi yang menunjukkan spesies P.disjunctivus, dan pola campuran antara spot hitam dengan vermikulasi yang menunjukkan hybrid (Gambar 4).

Pola yang pertama adalah titik-titik spot hitam yang disebut Pterygoplichthys pardalis (Gambar 4A). Pola kedua didapat 1 sampel (sampel ke-30), yaitu vermikulasi atau berlekuk-lekuk (Gambar 4B) dan disebut Pterygoplichthys disjunctivus. Pola ketiga yang didapat adalah campuran antara titik-titik spot hitam dengan vermikulasi (Gambar 4C) atau disebut hybrid (Page 1994; Page \& Robins 2006; Armbruster \& Page 2006; Wu et al. 2011; Bijukumar et al. 2015). 


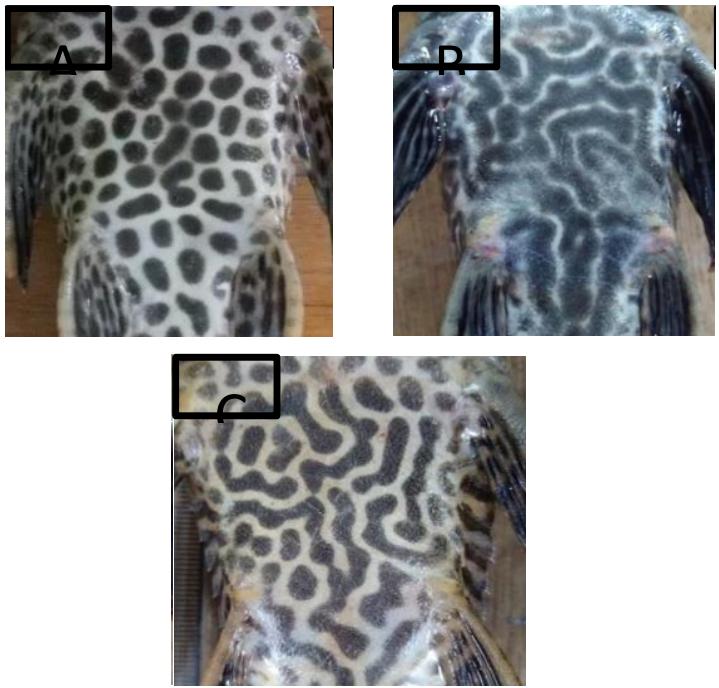

Gambar 4. Pola abdomen (A) titik-titik spot hitam [P.pardalis], (B) berlekuk-lekuk atau vermikulasi [P.disjunctivus], (C) campuran antara titik-titik spot hitam dengan berleluk-lekuk [hybrid]

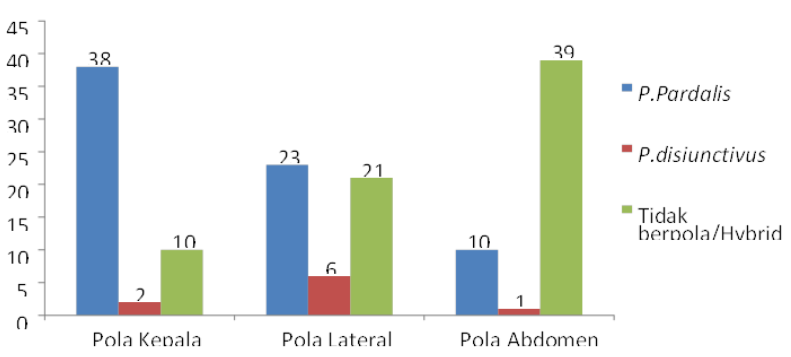

Gambar 5. Perbandingan hasil identifikasi berdasarkan 3 karakter morfologi

Identifikasi berdasarkan pola abdomen menunjukkan individu terbanyak adalah hybrid $78 \%$, Pterygoplichthys pardalis $(20 \%)$ dan Pterygoplichthys disjunctivus (2\%). Hasil penelitian ini sesuai dengan penelitian terhadap Ikan Genus Pterygoplichthys yang diperoleh pada beberapa populasi di Florida. Beberapa individu memiliki pola titik-titik pada bagian ventralnya, beberapa ada yang memiliki pola ventral yang berlekuk-lekuk, dan sebagian besar lainnya memiliki pola yang tercampur antara titik-titik dan berlekuk-lekuk (hybrid) (Nico et al. 2012).

Page \& Robins (2006) mengatakan bahwa di Indonesia hanya terdapat 2 spesies ikan sapusapu, yaitu P.pardalis dan P.disjunctivus. Pola abdomen antara spesies P.pardalis dan P.disjunctivus terkadang sulit untuk dibedakan. $\mathrm{Wu}$ et al. (2011) mengatakan bahwa spesies P.pardalis memiliki pola abdomen titik-titik hitam, P.disjunctivus memiliki pola berlekuk- lekuk dan spesies hybrid memiliki pola gabungan diantara keduanya.

Penelitian yang dilakukan oleh $\mathrm{Wu}$ et al. (2011) mendapatkan hasil 2 hipotesis dan 1 spekulasi. Hipotesis pertama P.disjunctivus kemungkinan merupakan spesies yang sama dengan P.pardalis. Hipotesis kedua yaitu populasi eksotik mungkin berasal dari hibridisasi diantara 2 spesies. Spekulasinya adalah spesies hybrid memiliki keunggulan adaptasi dibandingkan spesies non-hybrid. Apabila spekulasi tersebut benar maka hal itu yang menyebabkan jenis hybrid lebih banyak dari 2 spesies lainnya.

Identifikasi dengan melihat 3 karakter morfologi memberikan hasil yang berbeda. Jumlah individu terbanyak berdasarkan karakter pola kepala dan pola lateral adalah P.pardalis, sedangkan berdasarkan pola abdomen adalah hybrid (Gambar 5). Ketika dilakukan identifikasi dengan melihat ke-3 karakter, terdapat beberapa sampel yang masuk pada grup berbedaHal tersebut disebabkan oleh berkembangnya ilmu pengetahuan. Pengelompokkan hybrid berdasarkan pola abdomen pertama kali dilakukan oleh $\mathrm{Wu}$ et al. (2011)

\section{SIMPULAN}

Variasi morfologi ikan sapu-sapu Genus Pterygoplichthys asal sungai Ciliwung menunjukkan bahwa berdasarkan pola kepala dan pola lateral persentase individu P.pardalis lebih dominan dibandingkan spesies lain yaitu $76 \%$ dan $46 \%$, sedangkan berdasarkan pola abdomen menunjukkan bahwa hybrid merupakan jenis yang dominan $(78 \%)$

\section{UCAPAN TERIMA KASIH}

Terimakasih kepada Universitas Al Azhar Indonesia yang telah memberi dana Penelitian Grant UAI 2015 melalui Lembaga Penelitian dan Pengabdian Masyarakat (LP2M) UAI berdasarkan Surat Perjanjian Kerja Internal Pelaksanaan RE TA 2015 No. 040/SPK/A01/UAI/XI/2015, sehingga penelitian ini dapat terlaksana dengan baik. 
Kepada seluruh jajaran TNI Kodam Jaya dan para personil TNI selaku operator LCR dan pendamping di lapangan, terima kasih yang sebesar-besarnya atas dukungan, bantuan, dan kerjasamanya selama pelaksanaan kegiatan sampling di sepanjang aliran Sungai Ciliwung (Agustus-November 2015).

\section{DAFTAR PUSTAKA}

[1] Bijukumar A, Smrithy R, Sureshkumar U, George S. 2015. Invasion of South American suckermouth armoured catfishes Pterygoplichthys spp. (Loricariidae) in Kerala, India-a case study. J. of Threatened Taxa. 7(3):6987-6995.

[2] Fishbase. 2015. Scientific names where Genus equals Pterygoplichthys. http://fishbase.org/Nomenclature/Scientifi cNameSearchList.php? critl fieldname $=S$ $\underline{Y N O N Y M S . S y n G e n u s \& \text { crit } 1 \text { fieldtype }=C}$ HAR\&crit1 operator $=E Q U A L \&$ crit 1 val ue $=$ pterygoplichthys \& crit 2 fieldname $=S Y$ NONYMS.SynSpecies\&crit2_fieldtype $=C$ HAR\&crit 2 operator $=C O N T A I N S \&$ crit 2 value $=\&$ typesearch $=$ simple \& group $=$ sum mary\&backstep $=-2 \&$ sortby $=$ validname

(Diakses Pada 14 Desember 2015)

[3] Hadiaty RK. 2011. Diversitas dan hilangnya jenis-jenis ikan di Sungai Ciliwung dan Sungai Cisadane. Berita Biologi. 10(4):491-504.

[4] Hendrawan D. 2008. Kualitas air Sungai Ciliwung ditinjau dari parameter minyak dan lemak. Jurnal Ilmu-Ilmu Perairan dan Perikanan Indonesia. 15(2): 85-93.

[5] Hill AM, Lodge DM. 1999. Replacement of resident crayfishes by an exotic crayfish: the roles of competition and predation. Ecol. App. 9(2) 678-690.
[6] International River Foundation. 2011. Help Save The Ciliwung River Indonesia. http://www.riverfoundation.org.au/event.p $h p ? e=1289$. (Diakses Pada 10 September 2015).

[7] Mallet J. 2007. Hybrid speciation. Nature. 446:279-283.

[8] Nico LG, Martin RT. 2001. The South American armored catfish, Pterygoplichthys anisitsi (Pisces: Loricariidae), in Teas, with comment on foreign fish introduction in the American Southwest. The Southwestern Naturalist 46(1) 98-104.

[9] Nico LG, Butt PL, Johnston GR, Jelks HL, Kail M, Walsh SJ. 2012. Discovery of South American suckermouth amored catfish (Loricariidae, Pterygoplichthys spp.) in the Santa Fe River drainage, Suwannee River Basin, USA. Bioinv Rec. 1(3): 179-200.

[10] Page LM, Robins RH. 2006. Identification of sailfin catfishes (Teleosti:Loricariidae) in south-eastern Asia. The Raff. Bull. of Zool. 54:455-457.

[11] Wowor D. 2010. Studi Biota Perairan dan Herpetofauna di Daerah Aliran Sungai (DAS) Ciliwung dan Cisadane: Kajian Hilangnya Keanekaragaman Hayati. Cibinong: Pusat Penelitian Biologi Lembaga Ilmu Pengetahuan Indonesia.

[12] Wu LW, Liu CC, Lin SM. 2011. Identification of exotic Sailfin Catfish species (Pterygoplichthys, Loricariidae) in Taiwan based on morphology and mtDNA sequences. Zool. Stud.. 50:235-246. 